\title{
O Tripé Inflation Targeting, Superávits Primários e Flutuação Cambial: Análise de Regimes Alternativos sob Choques de Oferta e Cambiais
}

\section{The Tripod Inflation Targeting, Primary Surpluses and Exchange Rate Fluctuation: Analysis for Alternative Regimes under Supply and Exchange Rate Shocks}

Ricardo Ramalhete Moreira*

Resumo: A combinação de metas para inflação, superávits primários e flutuação cambial sob choques de oferta e cambiais pode criar efeitos deletérios para a dinâmica econômica. Este trabalho realiza experimentos computacionais de simulação através de um modelo dinâmico e estocástico capaz de receber diferentes restrições. Em geral, mostra-se que sob choques de oferta e cambiais um arranjo mais adequado inclui metas para inflação flexíveis, superávits primários contracíclicos e alguma forma de controle de capitais, sem que se impeça a flutuação cambial, como forma de minimizar as perdas sociais.

Palavras-chave: Metas para inflação. Superávits primários. Flutuação cambial.

Abstract: The combination of inflation targeting, primary surpluses and flexible exchange rates, under exchange rate and supply shocks, can create undesirable effects on the economic dynamics. This paper runs computational experiments through a dynamic and stochastic economic model, which is able to receive alternative constraints. In general, it shows that, under supply and exchange rate shocks, an adequate policy regime includes flexible inflation targeting, anti-cyclical primary surpluses and some kind of short-term capital controls, without eliminating the free exchange rate fluctuation, as a means of minimizing the social losses.

Keywords: Inflation targeting. Primary surpluses. Exchange rate fluctuation.

JEL Classification: E52; E63; F32.

Professor no Programa de Pós-Graduação em Economia da Universidade Federal do Espírito Santo (Ufes). E-mail: ramalhete.s@gmail.com 


\section{1 lntrodução}

Nas últimas décadas, a gestão da política econômica, em determinados países, fundamenta-se largamente em três pilares:

a) a gestão monetária por meio do sistema de metas para inflação (inflation targeting);

b) a gestão fiscal através de metas para superávits primários;

c) a "gestão" externa por meio de livre flutuação cambial e mobilidade de capitais. Este tem sido o regime ou combinação de políticas no Brasil, em particular a partir de 1999, quando o país abandonou o regime de âncora cambial - liberalizando as flutuações da taxa de câmbio - e adotou o sistema de metas para inflação e para superávits primários.

Tomados individualmente, cada um desses pilares ou componentes de política econômica apresenta vantagens e desvantagens específicas, que podem ser destacadas pela literatura e analisadas em debates estanques. Entretanto, é com a combinação dessas políticas que a dinâmica econômica de um país pode sofrer sérias restrições diante de determinados choques, a depender de qual seja a configuração de cada uma das políticas em questão e, por consequência, a sinergia formada entre as mesmas.

Em especial, os choques de oferta, tais como os causados por variações nos preços das commodities - hoje cada vez mais recorrentes - e os choques cambiais, como efeito dos movimentos abruptos dos fluxos de capitais especulativos também não raros -, têm a capacidade de impor trajetórias indesejadas para variáveis econômicas relevantes nas economias que adotam aquela combinação de políticas. Isso parece ser mais provável quanto maior for:

a) a rigidez do sistema de metas para inflação face aos choques inflacionários;

b) a inflexibilidade das metas de superávits primários diante das variações da atividade econômica;

c) a mobilidade de capitais internacionais de curto prazo, sob o contexto de flutuação cambial.

O presente trabalho tem como objetivo acessar essa temática por meio da realização de alguns experimentos de simulação computacional, através de um modelo estocástico dinâmico com inflation targeting, superávits primários e flutuação cambial. Analisam-se diferentes regimes de política diante de ocorrências de choques de oferta e cambiais. Busca-se observar, diante dessas ocorrências, quais são as trajetórias apresentadas por variáveis relevantes, tais como inflação, taxa de crescimento do Produto Interno Bruto (PIB), taxas de juros, relação dívida 
pública/PIB e taxas de câmbio. Em geral, esses experimentos mostram que um regime convencional de política econômica cria piores dinâmicas para aquelas variáveis - i.e. dinâmicas mais voláteis -, quando a economia é sujeita aos choques de oferta e cambiais. Por regime convencional, entende-se um regime apoiado em metas rígidas para inflação, superávits primários pró-cíclicos e forte mobilidade de capitais de curto prazo. Por outro lado, um regime alternativo de política, formado por metas flexíveis para inflação, superávits primários contracíclicos e controles de capitais de curto prazo, parece ser capaz de minimizar as perdas econômicas (e sociais) causadas pelos choques impostos ao sistema estudado.

O artigo está dividido em cinco seções, além desta introdução. A seção 2 busca acessar o referencial teórico, subdividindo-o em três partes: uma primeira, que trata do regime de metas para inflação; uma segunda, que lida com a política de superávits primários; e uma terceira, que analisa a flutuação cambial, a mobilidade de capitais e a questão dos controles de capitais; com isso, abrange-se o referencial relativo ao tripé da política econômica contemporânea. A seção 3 apresenta o modelo dinâmico estocástico, que servirá de base para as simulações e análises à frente. A seção 4, por sua vez, mostra a metodologia dos experimentos e os resultados das simulações. Por fim, apresentam-se as considerações finais e as referências.

\section{Metas para Inflação, Superávits Primários e Câmbio Flutuante}

\subsection{Inflation Targeting, Choques e a Necessidade de Flexibilização}

O regime de metas para inflação (inflation targeting - IT) é uma forma de âncora nominal em que a estabilidade de preços é perseguida basicamente pelo anúncio de uma meta numérica para a taxa de inflação ou para um intervalo de inflação, ao longo de um prazo de tempo definido (MISHKIN, 1999). Nesse regime, o Banco Central ajusta seus instrumentos de política monetária, fazendo uso de informação considerada relevante para a determinação da inflação, com o intuito de levar as taxas inflacionárias corrente e prospectiva para as metas adotadas. Em geral, os países que adotam o regime de metas para inflação fazem uso de uma taxa nominal de juros de curtíssimo prazo ou taxa interfinanceira como instrumento de política (BALL, 1999; SVENSSON 1997, 1999).

Ademais, estabelecem-se procedimentos fundamentais de comunicação e transparência do Banco Central para com o público, no que diz respeito às informações relevantes que são consideradas na estratégia de política, às medidas tomadas quando de desvios entre a inflação observada e a meta e às expectativas da autoridade e do público quanto à dinâmica econômica futura. Acredita-se que uma atitude de maior transparência por parte do Banco Central facilita seu ganho 
de credibilidade e a consequente redução das taxas de sacrifício diante de casos de desinflação, ao permitir que o público tenha melhor base de informação para monitorar e avaliar os resultados econômicos observados face às metas e anúncios das autoridades (KING, 1996; MISHKIN, 1999).

Há um consenso relativo - entre os autores que defendem as virtudes do regime de inflation targeting - a respeito da necessidade de adoção de mecanismos de flexibilização ou de "cláusulas de escape", como instrumentos institucionais, que deem ao regime maior margem para lidar com choques inflacionários que não tenham origem no comportamento da demanda agregada e da atividade produtiva. Ou seja, choques inflacionários que não tenham origem em um gap do produto (diferença entre o nível de produto corrente e o nível de produto potencial ou normal de uma economia), tais como choques de oferta - altas em impostos, preços de alimentos, energia, combustíveis, assim como altas em salários e margens de lucro não decorrentes de maior atividade econômica - e cambiais devem ser combatidos apenas parcialmente, se combatidos. Isso teria a função básica de evitar custos e perdas sociais para a atividade econômica, emprego e renda.

Na prática, todos os países que adotam o regime de metas de inflação possuem relativa flexibilidade para acomodar, em algum grau, políticas de curto prazo voltadas para a estabilização do produto e emprego. Além disso, a fim de que não haja grandes perdas do produto, o processo de desinflação tem se mostrado gradual nesses países, uma vez que a meta de inflação escolhida tem convergido para a inflação desejável de longo prazo apenas após algum tempo, e à medida que as expectativas de inflação são gradualmente reduzidas. Logo, o regime de metas de inflação não está ligado necessariamente à hipótese de expectativas racionais (ER), tão cara aos novos clássicos dos anos 70 e a alguns novos keynesianos atuais, nem à hipótese de credibilidade perfeita. Autores como King (1996), Ball (1999) e Debelle e Fischer (1994), embora de linhagem teórica mainstream, mostram que, pelo menos durante o período de construção de reputação e credibilidade, as expectativas têm forte componente backward-looking (expectativas adaptativas). Isso estaria em consonância com o grande número de evidências empíricas acerca do forte componente inercial e autorregressivo da inflação e do produto em muitos países.

No Brasil, em particular, o regime de metas de inflação foi implantado no dia $1^{\circ}$ de julho de 1999, em paralelo ao abandono da âncora cambial. Foi o arcabouço institucional e operacional escolhido para o alcance daquele que seria o principal objetivo de longo prazo da política monetária: a manutenção de taxas de inflação reduzidas e estáveis. Esse objetivo estaria expresso no anúncio da própria meta de inflação, a qual seria a nova âncora nominal para as expectativas de inflação e decisões de política, pelo que se esperava com isso aumentar a transparência e a comunicação da autoridade monetária para com o público. 
Ademais, esperava-se com esta nova sistemática fornecer maior informação aos policy-makers no que respeita às relações entre as decisões de política de curto prazo e suas consequências de longo prazo. Bogdanski, Tombini e Werlang (2000) chamam a atenção para a importância inicial de uma meta de inflação brasileira decrescente no período 1999-2001. A elevação da inflação experimentada pelo país ao longo de 1999 seria motivada pelo choque de desvalorização do câmbio naquele ano, o que teria gerado uma elevação de certos preços once-for-all. Uma vez passado o choque, a inflação não teria comportamento de elevação. Logo, para acomodar o choque naquele ano inicial, fixou-se uma meta de inflação maior (8\%).

Como as autoridades acreditavam que o bom funcionamento do regime de metas permitiria uma trajetória declinante da inflação ao longo dos anos seguintes, as metas também foram fixadas em níveis gradualmente menores. No entanto, sabe-se que a economia brasileira, após 2000, experimentou ainda alguns casos em que os preços dos bens e serviços sofreram elevação não devido a choques de demanda agregada, e sim devido a episódios de desvalorização cambial, inércia de preços administrados e altas em preços de commodities.

Para Bofinger, Mayer e Wollmershauser (2006) a resposta da política monetária frente a um choque de oferta depende basicamente da preferência por estabilidade da inflação vis-à-vis a estabilidade do produto. Quanto maior a preferência por estabilidade do produto, mais parcimoniosa deve ser a elevação das taxas de juros para que se combata um choque de oferta. Assim, maior será a acomodação do choque e a preservação da produção e do emprego. Esta ideia basicamente segue a conclusão de autores como Bernanke e Mishkin (1997), Ball (1999a), Svensson (1997) e Clarida, Galí e Gertler (1999).

Por sua vez, Ball (1999b), entre outros, demonstra por que, em economias abertas, o regime de metas para inflação deve ser flexibilizado. Grosso modo, variações cambiais criam um efeito pass-through de repasse para os preços dos bens e serviços, cujo combate pela política monetária tem efeitos sobre a dinâmica produtiva e sobre o próprio comportamento da taxa de câmbio, aumentando sua volatilidade. Assim, o autor propõe que o Banco Central faça uso de um índice de preços - para balizar o regime - que expurgue os efeitos das variações transitórias do câmbio sobre a formação de preços de mercado. Ou seja, o $\mathrm{BC}$ deveria mirar uma meta de inflação para um índice de preços cuja aferição seja consistente com uma taxa de câmbio de equilíbrio, desconsiderando efeitos temporários de valorizações e desvalorizações cambiais. Óbvio que tal estratégia possui uma dificuldade conceitual e técnica em relação à definição e estimação de uma taxa de equilíbrio para o câmbio. De toda forma, sabe-se que a relação forte entre câmbio e juros, em especial entre câmbio e diferencial de juros (domésticos e externos), promove efeitos colaterais das variações deste último sobre uma série 
de variáveis econômicas relevantes. Pode-se dizer que um regime de metas para inflação que esteja sujeito a choques de oferta e cambiais recorrentes, e que não tome as devidas medidas de flexibilidade, estará criando uma tendência inevitável de volatilidade do câmbio, com consequências instáveis para a performance econômica de um país.

\subsection{Regimes de Política Fiscal e Superávits Primários}

Um governo precisa lidar com sua restrição orçamentária intertemporal. O fluxo de pagamentos não financeiros de toda natureza (não decorrentes de dívidas) e financeiros (decorrentes de dívidas) precisa ser coberto, ou com impostos, ou com novas dívidas, ou ainda com emissão de moeda, a chamada receita de senhoriagem. A literatura convencional sobre o assunto estabelece basicamente dois regimes de coordenação entre as políticas fiscal e monetária: o regime ricardiano e o regime não ricardiano.

Um regime ricardiano é um em que a satisfação da restrição orçamentária do setor público é feita sem o uso de emissão monetária (SARGENT, 1982). O governo deve ajustar seus saldos fiscais ao longo do tempo para manter sua solvência, sob um contexto no qual a política monetária segue um caminho próprio e não subordinado aos ímpetos fiscais ou políticos. Trata-se de um regime em que a política monetária é ativa, e a fiscal é passiva. Há, neste caso, dominância monetária (LEEPER, 1991).

Por outro lado, um regime não ricardiano é um em que o governo satisfaz sua restrição orçamentária ao longo do tempo influenciando de alguma forma a trajetória da política monetária, seja via emissão monetária seja via ajustes das taxas de juros (AIYAGARI; GERTLER, 1985; SARGENT, 1982). O setor público honra seus pagamentos não apenas por meio de saldos ficais ajustados, mas também por meio da passividade ou subordinação da política monetária. Assim, trata-se de um regime em que a política fiscal é ativa, e a monetária é passiva. Neste caso, existe dominância fiscal. Além disto, autores como Woodford (1995) e Cochrane (2001) associam os regimes não ricardianos a contextos em que, por afetarem a disposição do público em consumir, a política fiscal é capaz de influenciar a trajetória inflacionária. Trata-se da chamada teoria fiscal do nível de preços.

O debate sobre política de superávits primários, ${ }^{1}$ no Brasil em particular, segue basicamente a visão dessa literatura convencional, ao impor ao setor público a necessidade de acumular saldos fiscais primários superavitários com o

$1 \quad$ Saldos primários são os saldos do setor público, descontando-se os pagamentos de juros nominais decorrentes da dívida pública. Por sua vez, os saldos nominais incluem esses pagamentos financeiros. No Brasil, nos últimos anos, tem havido superávits primários (saldos primários positivos), porém déficits nominais (saldos nominais negativos), basicamente porque a conta de juros nominais é maior que os saldos primários. 
intuito de honrar os compromissos financeiros, ou seja, com o intuito de manter a atratividade e solvência da dívida pública ou sua estabilidade em relação ao PIB.

Giambiagi e Ronci (2004) chegam a propor uma "Lei de Solvência Fiscal" para o país que, junto à Lei de Responsabilidade Fiscal, forçaria o Setor Público brasileiro a adotar superávits primários mínimos necessários para a sustentabilidade de médio prazo da dívida pública como proporção do PIB.

A ideia é a de que são necessários mecanismos institucionais, e entendimento sobre a importância social do ajuste fiscal por parte das autoridades e políticos, a fim de que os superávits primários sejam adotados sob contexto de credibilidade e consistência temporal, reduzindo-se o trade-off entre ajuste fiscal e crescimento econômico. Assim, maiores superávits primários seriam acompanhados de uma tendência declinante para as expectativas inflacionárias, taxas de juros de curto prazo e dívida pública como proporção do PIB, num círculo virtuoso de crescimento sustentado.

Nessa perspectiva, no entanto, são desconsiderados alguns aspectos:

a) a natureza dos choques inflacionários enfrentados pela economia ao longo do tempo;

b) a forma com que o Banco Central responde a tais choques no âmbito de um regime de metas para inflação;

c) a transmissão dessa resposta para os saldos fiscais e para a dinâmica da dívida pública ao longo do tempo;

d) os impactos desses elementos sobre a dinâmica da atividade econômica e, por conseguinte, sobre a própria trajetória das variáveis fiscais relevantes em relação ao PIB;

e) a possibilidade de um canal estruturalista da inflação, em que maiores taxas de juros induzam segmentos oligopolizados a repassarem os custos financeiros mais elevados para os preços, o que torna ambíguo o efeito da política monetária sobre a inflação.

Quanto aos aspectos "a" e "b", trata-se da combinação entre metas para inflação (inflation targeting) e choques inflacionários de oferta ou cambiais. Autores como Ball (1999a, 1999b), Svensson (1999), Clarida, Galí e Gertler (1999) e Eichengreen (2002) mostram que quando uma economia enfrenta choques inflacionários que não são decorrentes da dinâmica da atividade econômica, a resposta antiinflacionária da política monetária pode ter impactos indesejáveis. Há um trade-off entre a volatilidade da inflação e a do produto quando os choques são de oferta ou cambiais: reduzir o nível da inflação implica reduzir o nível da atividade econômica, já que o choque inflacionário não teve origem na demanda agregada. Caso o regime de metas para inflação não ofereça mecanismos de acomodação desses choques, ou esses mecanismos sejam muito apertados, a economia pode conviver 
com uma tendência inevitável de elevadas taxas de juros de curto prazo, sob choques de oferta ou cambiais recorrentes.

Strachman (2009) mostra como os preços administrados no Brasil - preços de combustíveis, energia, transporte público, aluguéis, entre outros -, que são altamente sensíveis a variações cambiais e de preços internacionais, podem perpetuar um contexto de elevadas taxas de juros quando o país mantém metas para inflação ambiciosas. Assim, em países com forte efeito pass-through - i.e. de repasse de variações cambiais para os preços de bens e serviços - e com metas para inflação que não expurguem aquele efeito dos índices de preços adotados como balizadores da política monetária, tal como ocorre no Brasil, é possível que maiores superávits primários sejam acompanhados, paradoxalmente, de maiores déficits nominais e dívida pública/PIB, assim como de maiores taxas de juros e de fraca atividade econômica, justamente o oposto do que preveem os defensores das metas para superávits primários, a exemplo de Giambiagi e Ronci (2004).

Quanto aos aspectos "c" e "d", trata-se de analisar como a resposta do regime de metas para inflação em face de choques de custos ou cambiais impacta a dinâmica dos resultados fiscais. Caso a dívida pública esteja atrelada às taxas de juros de curto prazo, que são o instrumento de política monetária, o combate a choques inflacionários recorrentes pode trazer como efeito tanto uma dinâmica de reduzida atividade econômica quanto de deterioração dos resultados e indicadores fiscais do setor público. Neste caso, a imposição de um regime ricardiano a uma economia sujeita a choques de preços pelo lado da oferta e do câmbio, e sob regime "apertado" de metas para inflação, pode ser acompanhada de custos sociais crescentes e contínuos em termos de viés de baixo crescimento econômico e de quadros periódicos de quase-insolvência do setor público, a despeito de saldos primários expressivos.

Quanto ao aspecto "e", em casos de pressões inflacionárias, a elevação da taxa de juros pelo BC pode aumentar os custos financeiros dos agentes, elevando, ao invés de reduzir, a taxa inflacionária, através do que se convencionou chamar de efeito Wright Patman (KRIESLER; LAVOIE, 2007); de fato, para os pós-keynesianos e pós-kaleckianos, em especial, a inflação possui forte e sistemático componente de custos.

A combinação entre um regime de metas para inflação pouco flexível, choques inflacionários recorrentes que não tenham origem no campo da demanda agregada e um regime ricardiano de política fiscal pode fazer com que superávits primários crescentes sejam ineficazes e acompanhados de comportamentos fiscais e produtivos aquém dos que poderiam ser observados sob uma combinação alternativa de políticas, muito mais quando são levados em consideração efeitos pouco ou não assumidos pela literatura convencional, em especial o efeito recessivo dos superávits primários e os efeitos ambíguos citados das taxas de juros sobre a 
dinâmica inflacionária. Uma combinação alternativa de políticas fiscal e monetária poderia ser composta de um regime contracíclico de superávits primários e de um regime de metas de inflação mais flexível diante dos choques de oferta e/ ou cambiais. Essa combinação de políticas será analisada no modelo proposto e testado pelas simulações computacionais, feitas na sequência deste trabalho. Primeiro, contudo, resta adentrar no campo da dinâmica cambial.

\subsection{Flutuação Cambial, Mobilidade de Capitais e Dinâmica Econômica}

Em economias abertas, em especial em economias em desenvolvimento, o regime de flutuação cambial, combinado com livre mobilidade de capitais pelo balanço de pagamentos, proporciona uma correlação forte entre as variações das taxas básicas de juros domésticas e das taxas de câmbio ao longo do tempo.

Em outras palavras, considerando-se um mercado global de capitais de curto prazo (portfólio) que se ajusta quase instantaneamente, mudanças nos diferenciais entre as taxas de juros domésticas e externas criam mudanças nas decisões de alocação de recursos de elevada liquidez dos operadores financeiros globais, impactando os fluxos de capitais de curto prazo na economia doméstica e suas taxas de câmbio. Flutuação cambial e forte mobilidade de capitais estão associadas a uma maior volatilidade cambial, vulnerabilidade externa e perda de autonomia das políticas domésticas fiscal e monetária, em especial nas economias emergentes (TOBIN, 1978; EICHENGREEN, 1995; FERRARI-FILHO; PAULA, 2009).

Segundo a visão de Eichengreen (2002), economias emergentes com metas para inflação estão particularmente sujeitas a um viés de elevadas taxas de juros, sob flutuação cambial e mobilidade de capitais, devido ao que se chama de "fear of floating": as autoridades monetárias teriam uma aversão a depreciações cambiais, uma vez que as mesmas pressionariam a inflação ao consumidor através do efeito pass-through, dificultando o alcance das metas inflacionárias. Neste caso, as elevadas taxas de juros domésticas teriam como função - talvez não confessada pelos Bancos Centrais - manter a moeda doméstica apreciada e desta forma facilitar a estabilidade da inflação. O elevado diferencial entre taxas domésticas de juros e externas aumentaria a busca dos investidores estrangeiros por títulos domésticos atrelados àquelas primeiras; o consequente influxo de capitais de curto prazo, por sua vez, promoveria a apreciação da moeda nacional e a pressão baixista na inflação ao consumidor.

Da mesma forma, mudanças na confiança dos investidores estrangeiros, devido a fatores de política e economia internacional, que não tenham relação direta com os chamados fundamentos econômicos das economias emergentes, podem, no entanto, ter sérias consequências para o comportamento dos diferenciais de juros e das taxas de câmbio, e assim para as políticas monetária e fiscal nessas economias. Processos especulativos contras as moedas domésticas e afluxos 
de capitais forçam os Bancos Centrais a ajustarem as taxas de juros para evitarem depreciações cambiais indesejadas e desvios inflacionários em relação às metas adotadas. Por sua vez, os impactos desta resposta sobre os saldos fiscais são claros: maiores pagamentos de juros nominais pelos governos e crescimento nos déficits nominais - forçando as autoridades fiscais a aumentarem os superávits primários, caso queiram estabilizar a relação dívida pública/PIB.

A conjugação de uma resposta a choques cambiais por meio de elevação nas taxas de juros e de maiores superávits primários tem significativo efeito recessivo sobre a dinâmica produtiva. Neste caso, tanto via choques cambiais quanto choques de oferta em geral, o tripé inflation targeting, metas para superávits primários e flutuação cambial - com mobilidade de capitais de curto prazo - possui impactos restritivos para a atividade real, o emprego e a renda.

A eliminação da volatilidade cambial, à primeira vista, poderia ser facilmente feita por meio de um regime de câmbio fixo, ou de metas cambiais. Contudo, como bem argumenta Mishkin (1999) entre outros, uma âncora cambial tem como desvantagem a perda de autonomia da política monetária para lidar com objetivos que entrem em conflito com os fluxos requeridos de capitais internacionais. Manter uma determinada taxa de câmbio desejada, ou manter o câmbio em determinado intervalo desejado, significa aplicar uma política de taxas de juros com a finalidade básica de controlar os fluxos de capitais e as reservas internacionais do país, colocando-os em patamares necessários e consistentes com as taxas de câmbio requeridas.

O caso da economia brasileira, de 1995 até 1999, foi um típico exemplo de perda de autonomia da política monetária para lidar com objetivos domésticos para além da mera regulação de fluxos internacionais e reservas em dólares. Sob tal regime, processos especulativos contra a moeda doméstica, que pressionavam por desvalorizações cambiais, forçavam o Banco Central do Brasil a elevar a taxa básica de juros (taxa Selic) com o intuito de impedir a saída de capitais de curto prazo e manter a âncora cambial com o dólar - esse foi o mecanismo usado pelo país nos episódios em meio às crises do México (1995), dos tigres asiáticos (1997) e da Rússia (1998). Aqui, a âncora cambial e sua manutenção eram desestabilizadoras, ao potencializarem a desaceleração econômica e a deterioração das contas externas.

Uma determinada literatura analisa uma forma alternativa de se conter a volatilidade cambial, mesmo sob regime de livre flutuação do câmbio. O remédio seria a adoção de mecanismos de controles sobre influxos de capitais estrangeiros, em especial sobre os capitais de curto e curtíssimo prazo, tais como aplicações em títulos federais e ações. Pode-se adotar, por exemplo, exigências de prazos mínimos para a permanência dos capitais estrangeiros ingressantes e/ou impostos sobre os mesmos (FERRARI-FILHO; PAULA, 2009). 
Por outro lado, pode-se estimular a entrada de capitais estrangeiros diretos (IED), de longo prazo, como forma de compensar a possível queda do ingresso de capitais de curto prazo. Isto manteria os saldos da conta de capitais - necessários em especial para economias deficitárias em transações correntes no balanço de pagamentos -, apenas reduzindo a dependência em relação aos capitais especulativos. Desta forma, regras de controles de capitais não são acompanhadas necessariamente de queda no ingresso de poupança externa e, portanto, não comprometem necessariamente economias que ainda não tenham feito os devidos ajustes para diminuir a necessidade dos recursos externos; a finalidade de tais controles, logo, não é impedir excedentes na conta de capitais, porém estimular uma composição menos volátil desses excedentes, ou seja, estimular um influxo de poupança externa com perfil de longo prazo, gerador de emprego e renda, e com externalidades positivas para o resto da economia.

Políticas de controles de capitais voláteis, se bem aplicadas, podem reduzir a correlação entre as variações nos diferenciais de juros e os níveis das taxas de câmbio. Ao fazê-lo, os Bancos Centrais ganham maior margem para implementarem políticas visando o alcance de objetivos de crescimento econômico e de inflação doméstica e para responderem a choques, sem que isso culmine em movimentos indesejados nas taxas de câmbio.

\section{Um Modelo Dinâmico e Estocástico de Simulação com Inflation Targeting, Superávits Primários e Câmbio Flutuante}

O modelo a seguir pode ser considerado pertencente à atual tendência de modelos de equilíbrio geral estocástico dinâmico (Dynamic Stochastic General Equilibrium - DSGE) em pequena escala. Uma vez que tais modelos permitem uma simulação de trajetórias econômicas sob diferentes combinações para os parâmetros estruturais, os mesmos são importantes para responderem questões de avaliação de políticas sob distintas restrições e/ou hipóteses (WALSH, 2003). Neste sentido, tais modelos e suas simulações podem servir como guias ou informações adicionais para a tomada de decisão em variadas instâncias de políticas.

\subsection{Identidades e Equações Fiscais e Financeiras do Setor Público}

Parte-se de uma equação de comportamento da relação dívida pública/PIB do Setor Público Consolidado:

$$
\phi_{t}=\phi_{t-1}+\alpha_{1}\left(j_{t}-s p\right)+\varepsilon_{1 t}
$$

Onde $\phi_{t}$ é a relação dívida pública/PIB no período $t, j_{t}$ são os juros nominais a serem pagos pelo Governo e $s p_{t}$ é o superávit primário, ambos como proporção do PIB. O parâmetro $\alpha_{1}$ é maior que zero e $\varepsilon_{1 t}$ é um choque aleatório com média zero e 
variância constante (white noise shock). $\mathrm{O}$ valor de $\left(j_{t}-s p\right.$ ) nada mais é do que o déficit nominal do governo. O montante de juros a ser pago, por sua vez, é definido da seguinte maneira:

$$
j_{t}=\alpha_{2} i_{t} \phi_{t-1}+\varepsilon_{2 t}
$$

Onde $i_{t}$ é a taxa nominal de juros de curto termo definida pelo Banco Central e $\phi_{t-1}$ é a relação dívida pública/PIB herdada do período t-1; $\alpha_{2}$ é maior que zero e $\varepsilon_{2 t}$ um choque aleatório.

Em um regime ricardiano, a política fiscal é definida com o objetivo de manter as condições de solvência do governo, e a política monetária não está subordinada aos ímpetos fiscais. Ou seja, os pagamentos primários e de juros do governo não são financiados com receita de senhoriagem, nem com alterações da taxa básica de juros, a qual respeita o regime de metas para inflação. Assim, o superávit primário é decidido com o intuito de estabilizar a relação dívida pública/ PIB. Tem-se a regra de política fiscal, ou seja, a regra de superávit primário do Setor Público Consolidado:

$$
\mathrm{sp}_{\mathrm{t}}=\mathrm{sp}_{\mathrm{t}-1}+\mathrm{k}\left(\phi_{\mathrm{t}-1}-\phi_{\mathrm{t}-2}\right)+\varepsilon_{3 t}
$$

O superávit primário em t é tanto maior que o de t-1, quanto maior for $\phi_{t-1}$ em relação a $\phi_{t-2}$. Sendo $\mathrm{k}$ um coeficiente positivo que mede a sensibilidade da política fiscal em relação a variações passadas na relação dívida pública/PIB e $\varepsilon_{3 t}$ um choque aleatório de política fiscal.

\subsection{Determinação da Atividade Econômica e da Inflação}

É preciso especificar como são determinadas as dinâmicas da atividade econômica e da inflação na economia. Coloca-se uma função IS dinâmica:

$$
Y_{t}=Y p+\beta_{1}\left(Y_{t-1}-Y p\right)-\beta_{2}\left(i_{t-1}-i_{t-2}\right)-\beta_{3}\left(s_{t}-s_{t-1}\right)+\beta_{4}\left(e_{t-1}-e_{t-2}\right)+g_{1 t}
$$

Em que $Y_{t}$ é a taxa de crescimento do produto no período $t$, Yp a taxa de crescimento potencial do produto, $\mathrm{i}_{\mathrm{t} i \mathrm{i}}$ a taxa nominal de juros de curto termo observada no período $t-i, \mathrm{sp}_{t-i}$ o superávit primário no período t-i, $\mathrm{e}_{\mathrm{t}-\mathrm{i}}$ a taxa nominal de câmbio no período t-i; $g_{1}$ um choque de demanda, com média zero e variância constante (ruído branco). Os parâmetros $\beta_{1}, \beta_{2}, \beta_{3}$ e $\beta_{4}$ são positivos. Por sua vez, tem-se uma equação de Phillips dinâmica estruturalista, tal que:

$$
\mathrm{P}_{t}=\mathrm{P}^{\mathrm{T}}+\delta_{1}\left(\mathrm{P}_{\mathrm{t}-1}-\mathrm{P}^{\mathrm{T}}\right)+\delta_{2}\left(\mathrm{Y}_{\mathrm{t}-1}-\mathrm{Y}_{\mathrm{t}-2}\right)+\delta_{3}\left(\mathrm{i}_{\mathrm{t}-1}-\mathrm{i}_{\mathrm{t}-2}\right)+\delta_{4}\left(\mathrm{e}_{\mathrm{t}}-\mathrm{e}_{\mathrm{t}-1}\right)+\mathrm{g}_{2 t}
$$

Sendo $\mathrm{P}_{t}$ a taxa de inflação corrente e $\mathrm{P}^{\mathrm{T}}$ a meta de inflação. A equação diz que a inflação corrente depende positivamente dos desvios inflacionários passados em torno da meta, da variação passada da taxa de crescimento do produto e da variação passada da taxa de juros de curto termo, o que descreve uma natureza estruturalista da taxa de inflação, em linha com modelos de inflação de custos póskaleckianos e pós-keynesianos (SMITHIN, 2009; MOREIRA, 2012); além disto a 
variação corrente da taxa de câmbio afeta positivamente a inflação em t. Os parâmetros $\delta_{1}, \delta_{2}, \delta_{3}$ e $\delta_{4}$ são positivos e $g_{2 t}$ é um choque de oferta, com média zero e variância constante.

Observa-se que a elevação das taxas de juros pelo $\mathrm{BC}$, para controlar a inflação por meio de contrações da atividade, pode ter o efeito contrário sobre os preços, por meio de uma inflação de custos financeiros. Isto vai depender basicamente dos valores relativos dos parâmetros $\beta_{2}, \delta_{2}$ e $\delta_{3}$.

\subsection{Regra de Política Monetária sob Inflation Targeting}

O Banco Central possui uma regra de política monetária, sob um contexto de metas para inflação. Essa regra segue o padrão das regras tradicionais de Taylor, em que os desvios da atividade econômica e da inflação são os principais argumentos levados em consideração. Assim:

$$
\mathrm{i}^{\mathrm{T}}=\mathrm{r}^{*}+\mathrm{P}^{\mathrm{T}}+\left[\lambda_{1}\left(\mathrm{Y}_{\mathrm{t}-1}-\mathrm{Y}_{\mathrm{t}-2}\right)+\lambda_{2}\left(\mathrm{P}_{\mathrm{t}-1}-\mathrm{P}^{\mathrm{T}}\right)\right]
$$

Sendo $\mathrm{i}_{\mathrm{t}}^{\mathrm{T}}$ a meta ótima de taxa de juros de curto termo, em $\mathrm{t}$, definida pelo $\mathrm{BC} ; \mathrm{r}^{*}$ a taxa natural de juros e $\mathrm{P}^{\mathrm{T}}$ a meta para a inflação; $\lambda_{1} \mathrm{e} \lambda_{2}$ são parâmetros positivos. Ainda, assume-se que o BC ajusta as taxas de juros de curto termo dando peso especial aos valores adotados em períodos passados, reconhecendo-se o que a literatura chama suavização das taxas de juros (interest rates smoothing) (GALÍ; GERTLER, 2007). Logo:

$$
\mathrm{i}_{\mathrm{t}}=(1-\rho) \mathrm{i}_{\mathrm{t}}^{\mathrm{T}}+\rho \mathrm{i}_{\mathrm{t}-1}
$$

Sendo $i_{t}$ a meta efetiva de taxa de juros praticada pelo BC; $\rho$ é o coeficiente (maior que zero e menor que 1) de suavização da taxa de juros, que mostra o peso dado a $i_{t-1}$ na formação da taxa básica corrente.

\subsection{Paridade de Juros e Formação do Câmbio}

Os investidores internacionais possuem comportamento especulativo diante das diversas opções de títulos de renda fixa no mundo, levando em consideração seus diferencias de juros, as possíveis variações de câmbio entre as moedas e os riscos soberanos. Logo, Assume-se uma condição de paridade de juros tal qual:

$$
\mathrm{i}_{\mathrm{t}}=\mathrm{i}^{*}{ }_{\mathrm{t}}+\tau\left(\mathrm{e}_{\mathrm{t}+1}^{\mathrm{e}}-\mathrm{e}_{\mathrm{t}}\right)
$$

Sendo $i^{*}{ }_{t}$ a taxa estrangeira de juros de referência, $e^{e}{ }_{t+1}$ a taxa de câmbio esperada para $t+1$ e $e_{t}$ a taxa corrente de câmbio. $O$ parâmetro positivo $\tau$ indica a sensibilidade dos juros domésticos às variações no diferencial esperado da taxa de câmbio. Tomando a expectativa de taxa de câmbio como determinada pelo câmbio em t-1 $\left(\mathrm{e}_{\mathrm{t}+1}^{\mathrm{e}}=\mathrm{e}_{\mathrm{t}-1}\right)$ e isolando a taxa de câmbio corrente, tem-se a seguinte regra de correlação inversa entre câmbio e juros, adicionando-se ainda um choque cambial aleatório (white noise): 


$$
e_{t}=e_{t-1}-\tau^{*}\left(i_{t}-i^{*}\right)+\varphi_{t}
$$

Pela equação 9, verifica-se uma correlação inversa entre o diferencial de juros $\left(i_{t}-i^{*}\right)$ e a taxa de câmbio corrente, sendo $\tau^{*}=(1 / \tau)>0$. Em outras palavras, dada a taxa de câmbio passada e a taxa de juros internacional, uma elevação da taxa básica de juros doméstica é acompanhada de uma apreciação (queda) cambial; e uma redução da taxa básica doméstica é acompanhada de uma depreciação (elevação) cambial. Isto ocorre pelo estilizado comportamento especulativo dos investidores internacionais. Um aumento do diferencial torna mais atrativa a compra de ativos domésticos de renda fixa, em relação à compra de ativos estrangeiros, forçando uma redução da taxa de câmbio, dado o maior influxo de divisas.

O parâmetro $\tau^{*}$ é importante porque dá a sensibilidade do câmbio em face de variações no diferencial de juros. Pode-se dizer que quanto maior a mobilidade de capitais estrangeiros de curto prazo em uma economia, maior será $\tau^{*}$. Em tese, por outro lado, medidas de controle e restrição de capitais de curto prazo podem amenizar a volatilidade cambial diante de mudanças no diferencial de juros e na percepção de risco dos investidores, reduzindo $\tau^{*}$. Por fim, o componente $\varphi_{t}$ - um choque com media zero e variância constante - expressa fatores não sistemáticos modificando a taxa de câmbio corrente, tais como mudanças na percepção de risco dos investidores estrangeiros e mudanças nas políticas financeiras internacionais.

\section{Metodologia e Resultados das Simulações}

Os experimentos computacionais serão realizados para dois regimes alternativos de política. As trajetórias dinâmicas da economia serão simuladas através do processo conhecido como calibração, que nada mais é do que a adoção de certos valores para os parâmetros e para as condições iniciais do sistema, a fim de que seja verificada uma convergência ou correspondência relativa entre os resultados da simulação e alguns fatos estilizados, ${ }^{2}$ ou seja, relações ou fenômenos regulares entre variáveis relevantes e, portanto, previstas pela ciência econômica.

Seja um regime convencional de política econômica, em que a economia está sujeita à seguinte combinação de políticas:

a) metas rígidas para inflação - baixa acomodação dos choques de oferta e cambiais, expressa por maiores valores para $\lambda_{2}\left(\lambda_{2}=\lambda_{2}{ }^{c}\right.$ sob regime convencional) e menores valores para $\rho\left(\rho=\rho^{c}\right.$ sob regime convencional);

2 Trata-se da definição dada por Hansen e Heckman (1996) para o processo de calibração. 
b) regra ortodoxa de superávits primários, dada pela equação (3), em que o superávit primário é ajustado tão somente pelas variações na relação dívida pública/PIB;

c) forte mobilidade de capitais especulativos (ausência ou semiausência de controles de capitais de curto prazo), em que mudanças no diferencial de juros e na percepção dos investidores estrangeiros criam forte volatilidade cambial, expressa por elevados valores de $\tau^{*}\left(\tau^{*}=\tau^{* c}\right.$ sob regime convencional).

Por outro lado, tem-se um regime não convencional de política econômica, composto por:

a) metas flexíveis para inflação - alta acomodação dos choques de oferta e cambiais, expressa por menores valores para $\lambda_{2}\left(\lambda_{2}=\lambda_{2}{ }^{n}\right.$ sob regime não convencional) e maiores valores para $\rho\left(\rho=\rho^{n}\right.$ sob regime não convencional);

b) regra contracíclica de superávits primários, substituindo (3), dada por: - (3') $\mathrm{sp}_{\mathrm{t}}=\mathrm{sp}_{\mathrm{t}-1}+\mathrm{k}\left(\phi_{t-1}-\phi_{t-2}\right)+\mathrm{k}^{\prime}\left(\mathrm{Y}_{\mathrm{t}-1}-\mathrm{Y}_{\mathrm{t}-2}\right)$

c) em que o superávit primário em t é ajustado pelas variações da relação dívida pública/PIB, e também pelas variações da taxa de crescimento do PIB, dado o parâmetro positivo k';

d) baixa mobilidade de capitais especulativos (adoção de controles de capitais de curto prazo), em que o câmbio é menos volátil diante de mudanças no diferencial de juros e na percepção dos investidores, o que se traduz por menores valores de $\tau^{*}\left(\tau^{*}=\tau^{* n}\right.$ sob regime não convencional).

Assim, colocam-se os dois regimes representados na Tabela 1.

Tabela 1 - Regimes convencional e não convencional de política econômica frente a choques de oferta e cambiais

\begin{tabular}{|c|c|c|}
\hline & Regime convencional & Regime não convencional \\
\hline Política monetária & $\lambda_{2}^{c} \boldsymbol{e} \rho^{c}$ & $\begin{array}{l}\lambda_{2}{ }^{\mathrm{n}} \boldsymbol{e} \rho^{\mathrm{n}} \\
\text { Sendo } \lambda_{2}{ }^{c}>\lambda_{2}{ }^{\mathrm{n}} \boldsymbol{e} \rho^{c}<\rho^{\mathrm{n}}\end{array}$ \\
\hline Política fiscal & (3) $\mathrm{sp}_{t}=\mathrm{sp}_{\mathrm{t}-1}+\mathrm{k}\left(\phi_{t-1}-\phi_{t-2}\right)$ & $\left(3^{\prime}\right) \mathrm{sp}_{t}=\mathrm{sp}_{t-1}+\mathrm{k}\left(\phi_{t-1}-\phi_{t-2}\right)+\mathrm{k}^{\prime}\left(\mathrm{Y}_{\mathrm{t}-1}-\mathrm{Y}_{\mathrm{t}-2}\right)$ \\
\hline $\begin{array}{l}\text { Grau de mobilida- } \\
\text { de de capitais de } \\
\text { curto prazo }\end{array}$ & $\begin{array}{l}\text { Forte mobilidade: } \tau^{* c} \\
\text { (Ausência ou baixo grau de } \\
\text { controles de capitais) }\end{array}$ & $\begin{array}{l}\text { Baixa mobilidade: } \tau^{* \mathrm{n}} \\
\text { Sendo } \tau^{* \mathrm{c}}>\tau^{* \mathrm{n}} \\
\text { (Grau expressivo de controles de capitais) }\end{array}$ \\
\hline
\end{tabular}

Fonte: Elaboração própria.

Ambos os regimes serão aplicados ao modelo composto pelas equações já apresentadas, sendo que serão impostos dois tipos básicos de choques: 
a) um choque inflacionário de oferta, representado por um valor positivo dado à perturbação aleatória $g_{2 t}$ em determinado ponto do tempo de simulação;

b) um choque de desvalorização cambial, representado por um valor positivo para a perturbação aleatória $\varphi_{t}$ em certo ponto do tempo.

Dessa forma, a Tabela 2 mostra todos os valores dos parâmetros e condições iniciais usados nas simulações para os dois regimes, e sob as duas fontes de choques, de oferta e cambial:

Tabela 2 - Valores adotados para todos os parâmetros e as condições iniciais

\begin{tabular}{cccccc}
\hline $\mathbf{s p}_{\mathbf{t}-\mathbf{1}}$ & $\phi_{\mathbf{t}-1, \mathbf{t}-\mathbf{2}}$ & $\alpha_{\mathbf{1}}$ & $\alpha_{\mathbf{2}}$ & $\mathbf{k}^{\mathbf{2}}$ & $\kappa$ \\
\hline 3 & 50 & 0,7 & 0,01 & 0,5 & 0,5 \\
$\mathrm{Yp}$ & $\beta_{1}$ & $\beta_{2}$ & $\beta_{3}$ & $\beta_{4}$ & $\delta_{1}$ \\
5 & 0,8 & 0,3 & 0,4 & 0,5 & 0,7 \\
$\delta_{2}$ & $\delta_{3}$ & $\delta_{4}$ & $\mathrm{r}^{*}$ & $\mathrm{P}^{\mathrm{T}}$ & $\lambda_{1}$ \\
0,1 & 0,6 & 0,7 & 2 & 4 & 0,5 \\
$\lambda_{2}{ }^{\mathrm{T}}$ & $\lambda_{2}{ }^{\mathrm{n}}$ & $\rho^{\mathrm{c}}$ & $\rho^{\mathrm{n}}$ & $\mathrm{e}_{\mathrm{t}-1, \mathrm{t}-2}$ & $\mathrm{Y}_{\mathrm{t}-1, \mathrm{t}-2}$ \\
1,5 & 1,2 & 0,8 & 0,9 & 3 & 5 \\
$\mathrm{i}^{*}$ & $\tau * \mathrm{c}$ & $\tau *^{\mathbf{n}}$ & $\mathrm{g}_{2 \mathrm{t}+1}$ & $\varphi_{\mathrm{t}+1}$ & $\mathrm{i}_{\mathrm{t}-1, \mathrm{t}-2}$ \\
6 & 0,9 & 0,2 & 2 & 1 & 6 \\
\hline
\end{tabular}

Fonte: Elaboração própria.

Deve-se frisar que a única preocupação foi a de adotar valores que não gerassem hipersensibilidades nas relações estruturais do sistema estudado, ou seja, valores que fossem consistentes com a estacionariedade das variáveis relevantes. Ademais, os valores na Tabela 2 são apenas uma combinação entre várias outras possíveis. No entanto, pode-se inferir que há um número considerável de combinações, no entorno da seleção adotada, que participa dos mesmos resultados qualitativos encontrados e analisados a seguir. Isto significa que embora não se possa, a priori, apontar para uma universalidade dos resultados das simulações a seguir, pode-se apontar para uma robustez relativa ou condicional das mesmas.

\subsection{Choque de Oferta}

Os Gráficos 1 a 5 no Apêndice A mostram as trajetórias das variáveis relevantes sob choques de oferta, em ambos os regimes de comparação; sendo as curvas cinzas e sólidas (__ para o regime convencional; e as curvas pretas e tracejadas (_ _ para o regime não convencional, em todos os gráficos. 
O choque de oferta de 2 pontos percentuais tem como efeito primário uma elevação abrupta e intensa da taxa de inflação, acima da meta de 4,0\% em ambos os regimes (6,0\%) (Gráfico 1). A resposta da política monetária, no entanto, é mais agressiva no regime convencional. Isto faz com que a taxa de juros doméstica seja aumentada para quase $6,8 \%$; no regime não convencional, contudo, a resposta é mais parcimoniosa e a taxa de juros é colocada em nível próximo a 6,5\% (Gráfico 2). O impacto dessas respostas diferenciadas de política monetária será absorvido também de forma distinta pela dinâmica da atividade econômica.

Sob o regime convencional, a economia sofre uma redução maior da taxa de crescimento do PIB (Gráfico 3), de 5\% para 3,9\%, além de apresentar maior volatilidade ao longo do tempo até que retome a trajetória de $5 \%$ ao período. Por outro lado, sob regime não convencional, a taxa de crescimento do PIB cai apenas de 5\% para 4,7\%, uma redução inexpressiva. Ademais, a taxa retorna para o nível de $5 \%$ com maior suavidade ao longo do tempo, se comparado com o que ocorre no regime convencional.

A razão dívida pública/PIB também apresenta trajetórias distintas sob ambos os regimes (Gráfico 4). No regime não convencional, sob choques de oferta, essa razão alcançou patamares maiores (50,74\%), se comparado com o observado no regime convencional (50,58\%), muito embora essa diferença seja marginal. A explicação para esta diferença está, em grande medida, na resposta de política fiscal, ou na resposta dos superávits primários sob ambos os regimes. No regime não convencional a resposta do superávit primário é contracíclica (equação 3'), ao passo que sob regime convencional há uma resposta ricardiana (equação 3).

Logo, como no último o superávit primário cresce em maior medida, a razão dívida/PIB sofre menor elevação no regime convencional, porém com impacto negativo sobre a atividade econômica, contribuindo para a grande queda da taxa de crescimento do PIB observada (Gráfico 3). Já no regime não convencional (equação 3'), o superávit primário é calibrado também para a variação da taxa de crescimento do PIB: como a resposta de política monetária impõe redução da atividade econômica, o superávit primário cresce menos diante da elevação da razão dívida pública/PIB, porém isto repercute positivamente sobre a dimensão do crescimento econômico, contribuindo para uma redução menor da taxa de crescimento do PIB.

A taxa de câmbio sofre efeito nitidamente mais forte sob regime convencional (Gráfico 5). A mesma cai de 3 unidades monetárias (u.m.) para 0,28 u.m., estabilizando-se em 0,83 u.m., ou seja, há uma apreciação cambial significativa, o que vai contribuir também para os efeitos deletérios sobre a taxa de crescimento do PIB. Esta grande apreciação sob o regime convencional se deve à ausência 
de controles de capitais. Neste caso, o diferencial de juros imposto pela política monetária - como resposta ao choque inflacionário - tem como efeito um maior influxo de capitais estrangeiros de curto prazo, depreciando a moeda externa em maior escala.

No regime não convencional, por sua vez, a apreciação cambial observada é moderada. A taxa de câmbio cai suavemente para 1,96 u.m.. Embora isto tenha efeitos danosos para a atividade econômica, os mesmos são amortecidos se comparado com o que sucede no regime convencional. A adoção de controles de capitais de curto prazo diminui a sensibilidade do câmbio às mudanças nos diferenciais de juros impostas pelo $\mathrm{BC}$, diferenciais que, inclusive, são menores no regime não convencional, dada a maior flexibilidade do regime de metas para inflação sob choques de oferta.

\subsection{Choques Cambiais}

Os Gráficos 6 a 10 no Apêndice B mostram as trajetórias das variáveis relevantes sob choques cambiais, em ambos os regimes de comparação; sendo as curvas cinzas e sólidas (__) para o regime convencional; e as curvas pretas e tracejadas (_ _ para o regime não convencional, em todos os gráficos.

Observa-se que o choque cambial de 01 ponto percentual impõe trajetórias diferentes sobre a economia, a depender de qual seja o regime de política pelo qual se responde. No caso convencional, inicialmente há uma depreciação cambial e consequente elevação da taxa de inflação (pelo efeito pass-through), a qual passa de uma taxa de 4,0\% para 4,7\% (Gráfico 7). Esses efeitos primários são os mesmos observados sob o regime não convencional.

No entanto, a partir da resposta de política monetária, e das respostas de arbitragem dos investidores a mudanças nos diferenciais de juros, observam-se desdobramentos distintos nos dois regimes. No caso convencional, em que opera um arcabouço rígido de metas para inflação, a taxa de juros doméstica sai de 6,0\% para 6,32\%, enquanto no regime não convencional, em que o arcabouço de metas para inflação é mais flexível, a taxa sai de 6,0\% para 6,19\% (Gráfico 8). Embora essa diferença seja diminuta, seus efeitos sobre a dinâmica da atividade econômica e do câmbio são expressivos.

A taxa de crescimento do PIB (Gráfico 9) sofre elevação como efeito primário da desvalorização cambial, via exportações líquidas. Em ambos os regimes ela sai de 5,0\% para um pico de 5,5\% ao período. Contudo, no regime convencional, após o maior aperto monetário mencionado, a taxa de crescimento apresenta queda de 0,7 ponto percentual (saindo de 5,5\% para 4,8\%), em apenas 04 períodos. Já no regime não convencional, a resposta da política monetária é consistente com um "pouso suave" da taxa de crescimento: após aproximadamente 11 períodos, a taxa retorna para seu valor estacionário de $5 \%$, sem que tenha apresentado valores 
menores do que este último. A maior volatilidade ou instabilidade do produto no regime convencional é nítida, se comparado com o regime alternativo.

No que diz respeito à razão dívida pública/PIB (Gráfico 10), esta inicialmente sofre uma pequena elevação no regime convencional (de 50\% para 50,22\%), ao passo que diminui quase imediatamente no regime alternativo (de 50\% para 49,9\%). Essas diferenças são também marginais, mas o motivo das mesmas é elucidativo. A resposta de política fiscal no regime não convencional é contracíclica, e isto significa um maior superávit primário, inicialmente, como resposta à elevação do crescimento do PIB. Como o aperto monetário em resposta a essa expansão é mais parcimonioso em relação ao que ocorre com o regime convencional, observa-se um superávit nominal na passagem do período 5 para o período 6 sob o regime alternativo.

No regime convencional, por outro lado, do período 4 ao período 8 há déficit nominal (juros da dívida maiores que o superávit primário), de forma que a razão dívida pública/PIB se eleva nesse ínterim. Embora essa razão se estabilize em ambos os regimes em seu valor tendencial (50\%) e as diferenças cíclicas de curto prazo sejam marginais (de até 0,32 ponto percentual), as mesmas poderiam ser significativas, caso os parâmetros $\alpha_{1}, \alpha_{2}$ e k apresentassem valores maiores do que os adotados na simulação corrente.

Por fim, a trajetória cambial é desfavorável sob regime convencional (Gráfico 6). Enquanto a taxa de câmbio se estabiliza em 3,64 u.m. no regime alternativo, no convencional a mesma repousa em 3,24 u.m. e através de maior volatilidade. Isto basicamente se deve ao fato de que há, no primeiro caso, mecanismos de controle de capitais de curto prazo aliados à política monetária mais flexível. Isto dá origem a menores diferenciais de juros e a uma menor sensibilidade cambial aos mesmos. Por outro lado, o regime convencional, como resposta aos choques cambiais, impõe maiores diferenciais de juros e maior sensibilidade cambial aos mesmos, visto que inexistem mecanismos de controle de influxos especulativos.

\section{Considerações Finais}

Choques de oferta e/ou cambiais podem exercer diferentes impactos sobre a dinâmica das variáveis relevantes de uma economia, a depender de qual seja o conjunto de políticas utilizado para responder aos desvios observados. Embora as políticas de metas para inflação, superávits primários e flutuação cambial tenham vantagens (e desvantagens) para a composição da política econômica, é importante que haja uma calibração adequada dessas políticas, a fim de que as instabilidades advindas das respostas aos choques observados sejam minimizadas.

Grosso modo, com base no modelo proposto e nas simulações que foram realizadas para fins de ilustração do argumento, pode-se dizer que: controles de 
capitais estrangeiros de curto prazo, aliados à política fiscal contracíclica e à política monetária flexível podem compor uma resposta de política econômica capaz de mitigar os efeitos desestabilizadores dos choques cambiais e de oferta ao longo do tempo.

A economia brasileira, nos últimos anos, tem sido exemplo de adoção simultânea das políticas de metas de inflação, superávits primários e livre flutuação cambial. Sua performance, no entanto, não tem sido das melhores a partir de 1999, na média, se comparada com a desempenhada por países como China e Índia, dentre outros. Algumas pistas podem ser usadas como hipóteses para esse contraste, muito embora esse tema seja de uma monta que não caberia neste trabalho.

Em 2011, em particular, foi ampla a discussão sobre uma apreciação excessiva do Real frente ao dólar estadunidense, como um dos efeitos do elevado diferencial de juros entre a taxa brasileira e as estrangeiras. Apesar das bandas inflacionárias do regime brasileiro de metas para inflação já funcionarem como um mecanismo de flexibilidade diante de choques de oferta e cambiais, a performance do país poderia ser alavancada se fossem adotados mecanismos efetivos de controles de capitais especulativos aliados a uma política de superávits primários com regra contracíclica, o que não tem sido implementado até aqui.

\section{Referências}

AIYAGARI, S. R.; GERTLER, M. The Backing of Government Bonds and Monetarism. Journal of Monetary Economics, Amsterdam, NL, v. 16, n. 1, p. 19-44, Jul. 1985.

BALL, L. Efficient rules for monetary policy. International Finance, Hoboken, v. 2, n. 1, p. $63-$ 83, Apr. 1999.

BALL, L. Policy rules for open economies. In: TAYLOR, J. (Ed.). Monetary Policy Rules. Chicago: University of Chicago Press, 1999. p. 127-144.

BERNANKE, B. S.; MISHKIN, F. S. Inflation targeting: a new framework for monetary policy? Journal of Economic Perspectives, Nashville, v. 11, n. 2, p. 97-116, Jul. 1997.

BOFINGER, P.; MAYER, E.; WOLLMERSHAEUSER, T. The BMW Model: A New Framework for Teaching Monetary Economics. Journal of Economic Education, New York, v. 37, n. 1, p. 98-117, 2006.

BOGDANSKI, J.; TOMBINI, A. A.; WERLANG, S. C. Implementing inflation targeting in Brazil. Working Paper Series, Brasília, n. 1, p. 1-29, Jul. 2000.

CLARIDA, R.; GALÍ, J.; GERTLER, M. The science of monetary policy: a new Keynesian perspective. The Journal of Economic Literature, Nashville, v. 38, n. 2, p. 1661-1707, Dec. 1999.

COCHRANE, J. H. Long-Term Debt and Optimal Policy in the Fiscal Theory of the Price Level. Econometrica, Chicago, v. 69, n. 1, p. 69-116, Jan. 2001.

DEBELLE, G.; FISCHER, S. How Independent Should a Central Bank Be? In: FUHRER, J. (Ed.). Goals, Guidelines, and Constraints Facing Monetary Policymakers. Boston: Federal Reserve Bank, 1994. p. 195-221. 
EICHENGREEN, B. Can Emerging Markets Float? Should They Inflation Target? Working Papers Series, Brasília, n. 36, p. 1-26, Feb. 2002.

EICHENGREEN, B.; TOBIN, J.; WYPLOSZ, C. Two Cases for Sand in the Wheels of International Finance. Economic Journal, Cambridge, GB, v. 105, n. 428, p. 162-172, Jan. 1995.

FERRARI-FILHO, F.; PAULA, L. F. Exchange rate regime proposal for emerging countries: a Keynesian perspective. Journal of Post-Keynesian Economics, Armonk, v. 31, n. 2, p. 227-248, Winter 2009.

GALÍ, J.; GERTLER, M. Macroeconomic Modeling for Monetary Policy Evaluation. Journal of Economic Perspectives, Nashville, v. 21, n. 4, p. 25-45, Fall 2007.

GIAMBIAGI, F.; RONCI, M. Fiscal Policy and Debt Sustainability: Cardoso's Brazil, 19952002. IMF Working Paper, Washington, n. 04/156, p. 1-43, Aug. 2004.

HANSEN, L.; HECKMAN, J. The empirical foundations of calibration. Journal of Economic Perspectives, Nashville, v. 10, n. 1, p. 87-104, Winter 1996.

KING, M. How should central banks reduce inflation? Conceptual issues. FED of Kansas City Economic Review, v. 4, 1996.

KRIESLER, P.; LAVOIE, M. The new view on monetary policy: The New Consensus and its Post-Keynesian critique. Review of Political Economics, New York, v. 19, n. 3, p. 387-404, Jul. 2007.

LEEPER, E. M. Equilibria Under 'Active' and 'Passive' Monetary and Fiscal Policies. Journal of Monetary Economics, Amsterdam, v. 27, n. 1, p. 129-47, Feb. 1991.

MISHKIN, F. S. International experiences with different monetary regimes. NBER Working Paper Series, Cambridge, US, n. 7044, Mar. 1999.

MOREIRA, R. R. Revisitando as críticas pós-keynesianas à nova síntese neoclássica: questões de política monetária. Revista Análise Econômica, Porto Alegre, v. 57, n. 1, p.77-105, mar. 2012.

SARGENT, T. J. The Ends of Four Big Inflations. In: HALL, R. E. (Ed.). Inflation: causes and effects. Chicago: University of Chicago Press, 1982.

SMITHIN, J. Teaching the new consensus model of 'monetary monetary economics' from a critical perspective: pedagogical issues. In: FONTANA, G.; SETTERFIELD, M. (Ed.). Macroeconomic Theory and Macroeconomic Pedagogy. London: Palgrave, 2009. p. 255-72.

STRACHMAN, E. Implementing inflation targeting in Brazil: an institutional analysis. MPRA Paper, Munich, v. 15131, May 2009.

SVENSSON, L. E. O. Inflation forecast targeting: implementing and monitoring inflation targets. European Economic Review, Amsterdam, v. 41, n. 6, p. 1111-1146, Jun. 1997.

SVENSSON, L. E. O. Inflation targeting as a monetary policy rule. Journal of Monetary Economics, Amsterdam, v. 43, n. 3, p. 607-54, Jun. 1999.

TOBIN, J. A Proposal for International Monetary Reform. Eastern Economic Journal, Bloomsburg, US, v. 4, n. 3-4, p. 153-159, Jul./Oct. 1978.

WALSH, C. E. Monetary Theory and Policy. 2nd ed. Cambridge: MIT Press, 2003.

WOODFORD, M. Price-Level Determinacy without Control of a Monetary Aggregate. Carnegie-Rochester Conference Series on Public Policy, Amsterdam, v. 43, p. 1-46, Dec. 1995. 
Apêndice A - Dinâmica das Variáveis Relevantes sob ambos os Regimes e Choques de Oferta Regime Convencional I_le Regime Não Convencional I_ I

Gráfico 1 - Taxa de inflação (P) sob choque de oferta

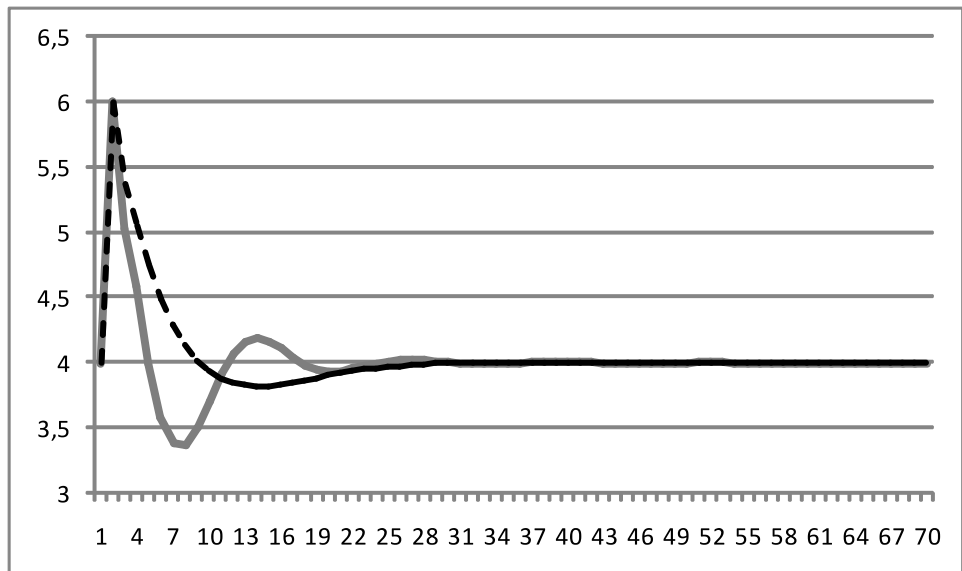

Gráfico 2 - Taxa de juros doméstica (i) sob choque de oferta

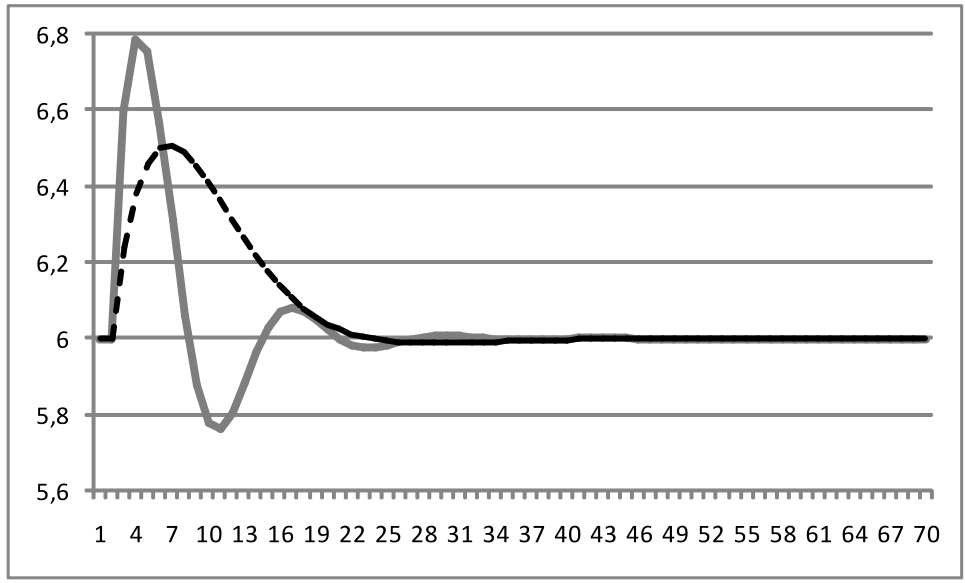

Gráfico 3 - Taxa de crescimento do PIB (Y) sob choque de oferta

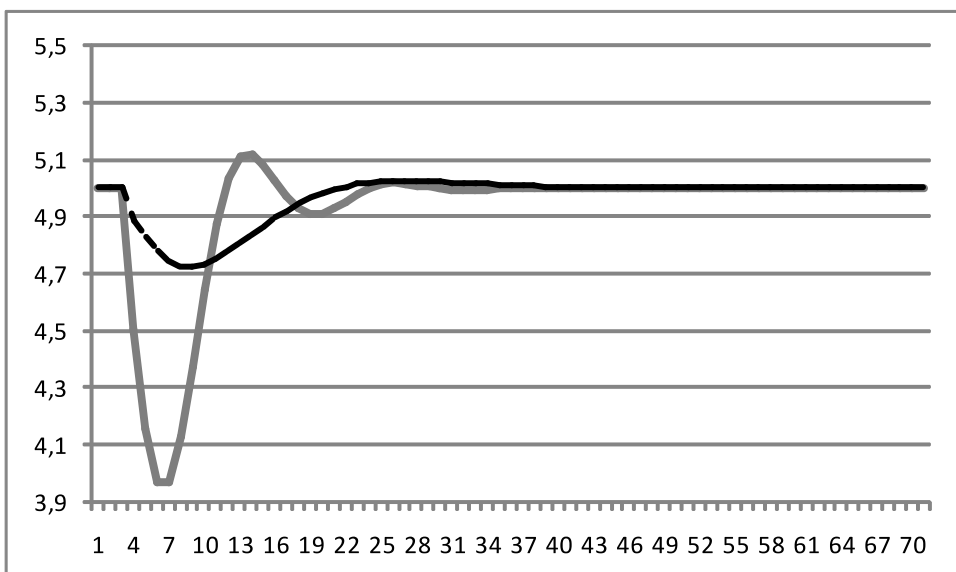


Gráfico 4 - Dívida pública/PIB ( $\phi)$ sob choque de oferta

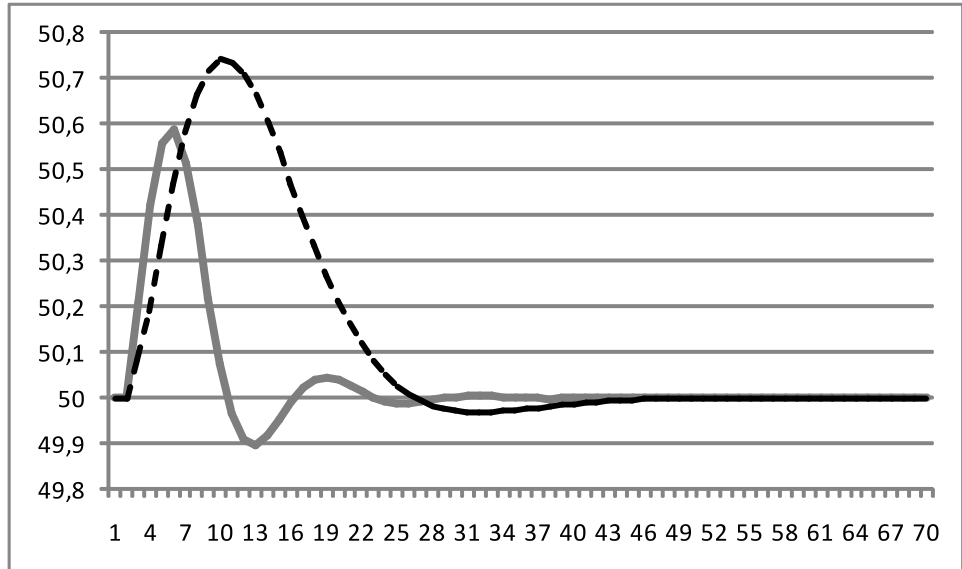

Gráfico 5 - Taxa de câmbio (e) sob choque de oferta

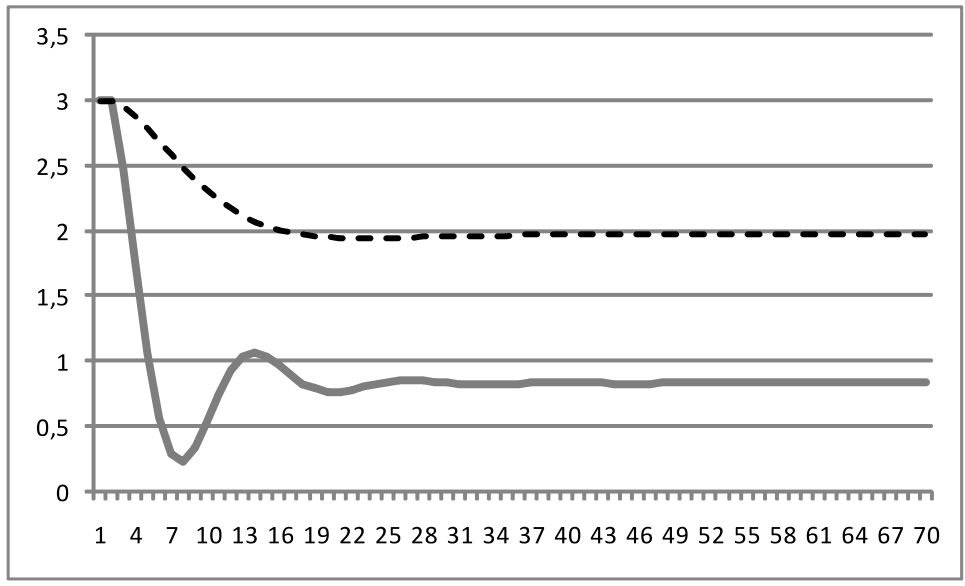


Apêndice B - Dinâmica das Variáveis Relevantes sob ambos os Regimes e Choques Cambiais Regime Convencional I_le Regime Não Convencional I_ I

Gráfico 6 - Taxa de câmbio (e) sob choque cambial

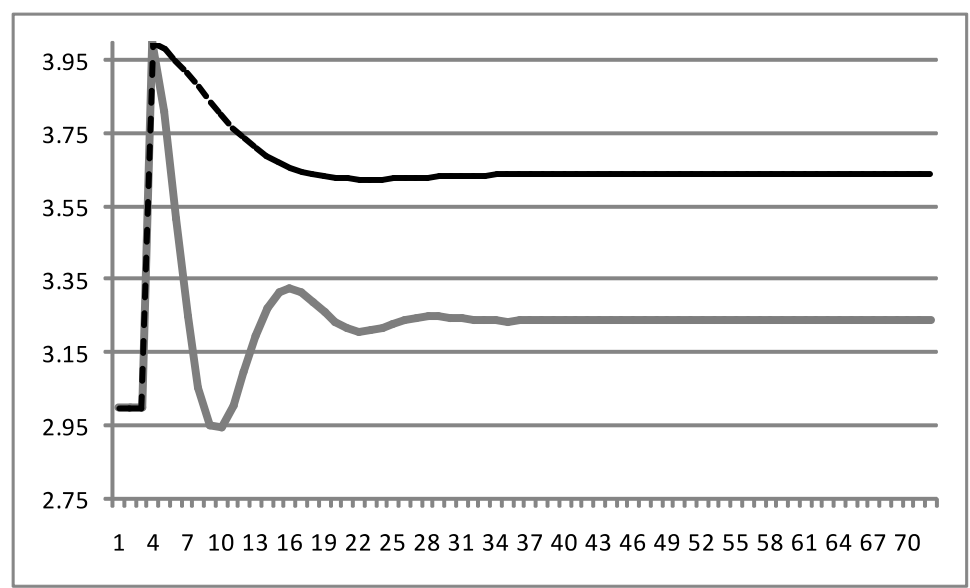

Gráfico 7 - Taxa de inflação (P) sob choque cambial

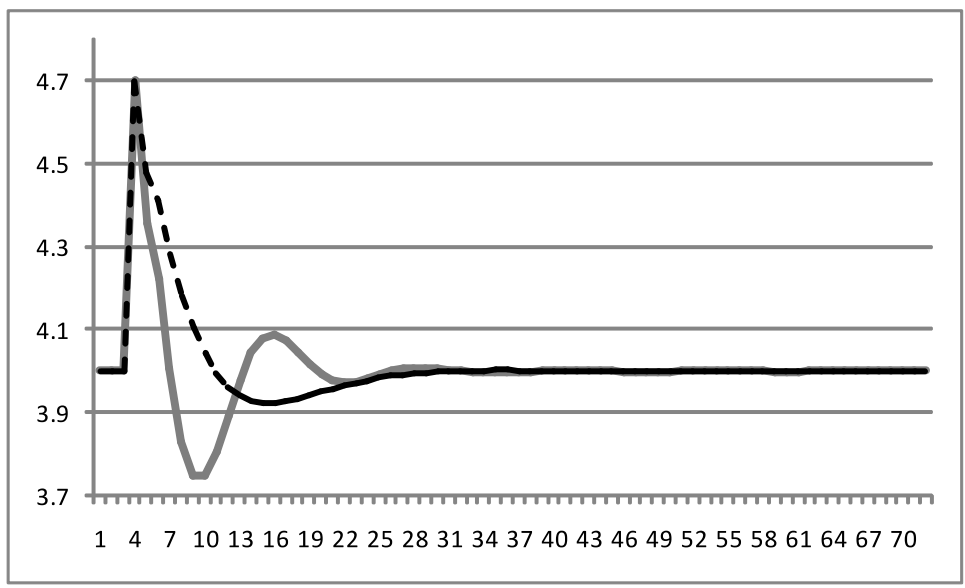

Gráfico 8 - Taxa de juros doméstica (i) sob choque cambial

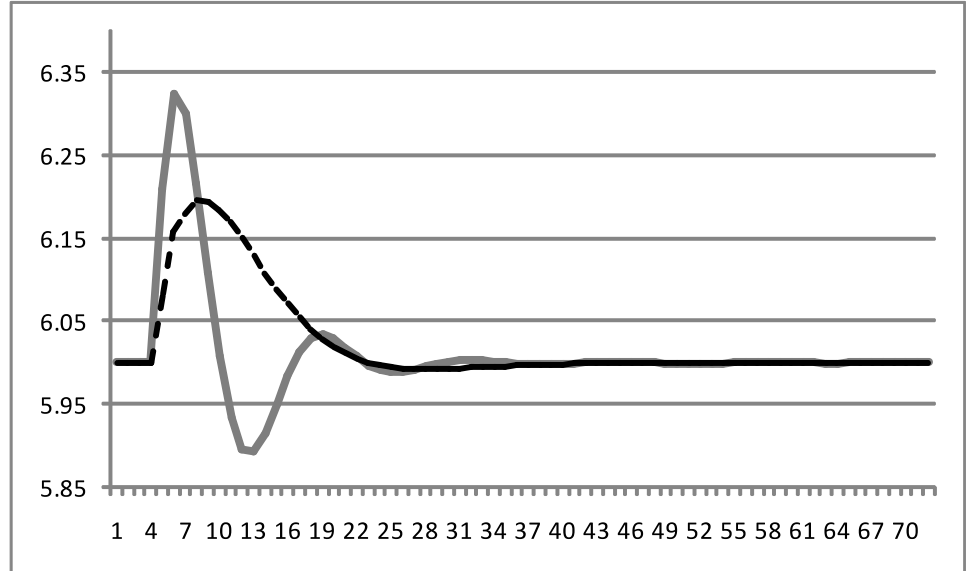


Gráfico 9 - Taxa de crescimento do PIB (Y) sob choque cambial

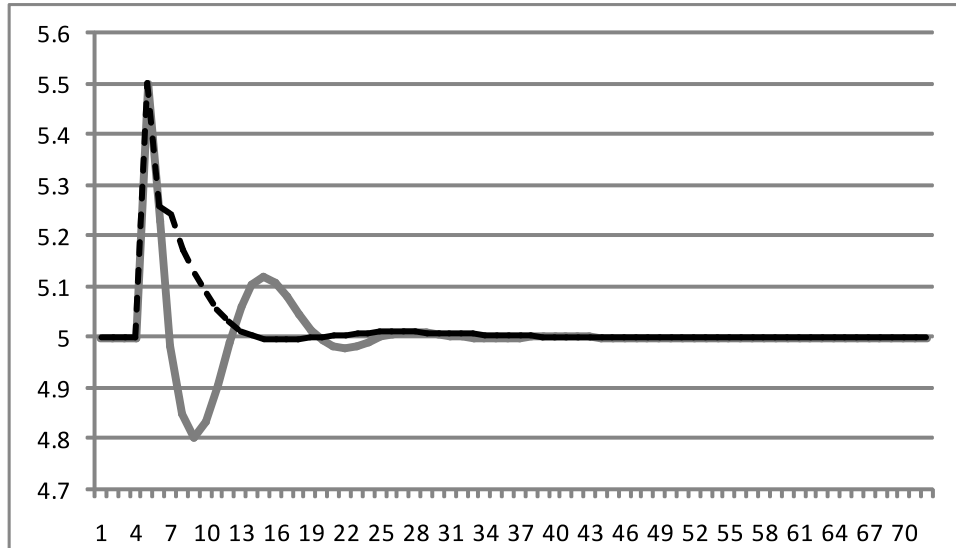

Gráfico 10 - Dívida pública/PIB ( $\phi)$ sob choque cambial

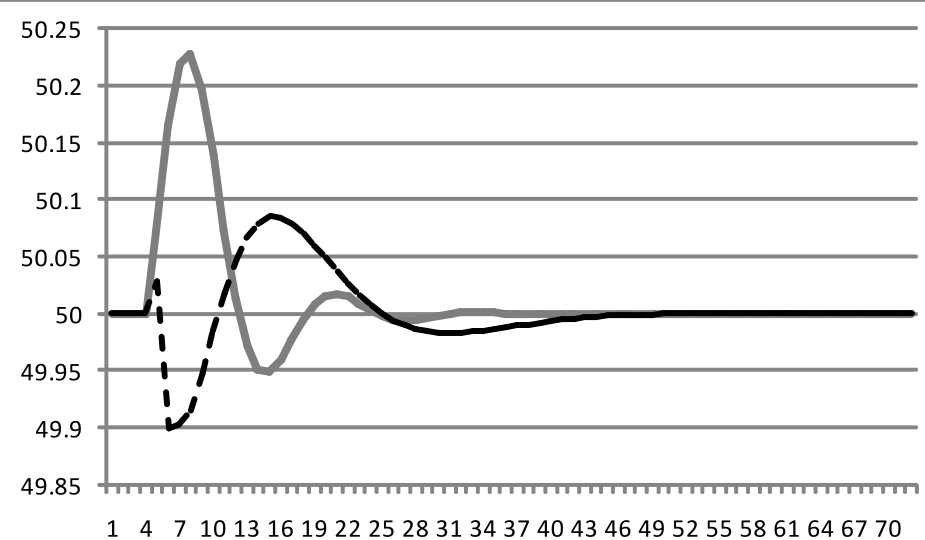

Recebido em: 17/08/2011.

Aceito em: 09/11/2012. 